\title{
Genome Analysis of Amaranthus dubius Mart. ex Thell. through the Study of Amaranthus spinosus $X$ A. dubius Hybrids
}

\author{
Bharati Behera and S. N. Patnaik \\ Cytogenetics Laboratory, Post-Graduate Department of Botany, \\ Utkal University, Bhubaneswar, India
}

Received May 20, 1980

Amaranthus spinosus $\mathrm{L}$. is a common weed throughout the warmer parts of the world whereas Amaranthus dubius Mart. ex Thell. is mostly cultivated as a pot herb. Plants of $A$. dubius are found in open fields as garden escapes and grow synpatrically with $A$. spinosua. A. dubius is a tetraploid species with $\mathrm{n}=32$ where as $A$. spinosus is a diploid species characterised by $n=17$. Natural interspecific hybrids between these two species are frequent and have long been noticed. The oldest record of its spontaneous occurrence was in the Berlin Botanical garden (Thellung 1914) which dates back to 1874. Since then, many investigators viz. Thellung (1914), Clifford (1959), Grant (1959) and Pal (1972) reported the occurrence of natural interspecific hybrids between these two species. But the hybrids attain a high degree of sterility $(88-92 \%)$ which accounts for the breakdown of the hybrid swarm. Grant (1959) made the first cytological analysis of the hybrids and revealed interesting genome relationships between the two species. Pal (1972) not only studied the cytology of the hybrids but raised hexaploid plants by treating the triploid hybrids with colchicine. During the present investigation interspecific hybrids between these species were frequently noticed in the garden. The cytology of the hybrids was studied and hexaploid plants were obtained by treating the triploid hybrids with colchicine. Study of the hexaploids through the $\mathrm{C}_{0}, \mathrm{C}_{1}$ and $\mathrm{C}_{2}$ generations revealed some abnormal cytotypes not hitherto described which have interesting bearings on the genome relationships of these two species.

\section{Materials and methods}

Seeds collected from $A$. dubius always gave rise to some hybrids. In an effort to induce polyploidy in $A$. dubius, seedlings were raised some of which turned out to be triploid hybrids. The seedlings were treated with 0.2 percent aqueous solution of colchicine, supplied to their tips. Polyploidy could be induced in one such hybrid which was cytologically tested. This plant was studied through $F_{2}$ and $F_{3}$ generations characterised by several different cytotypes. Cytological analysis was made of meiosis of the pollen mother cells following aceto-carmine squashing. Pollen sterility was studied in staining the pollen in a mixture of glycerine and acetocarmine $(1: 1)$.

The expected frequency of bivalents in the $F_{1}$ hybrids was calculated by the 


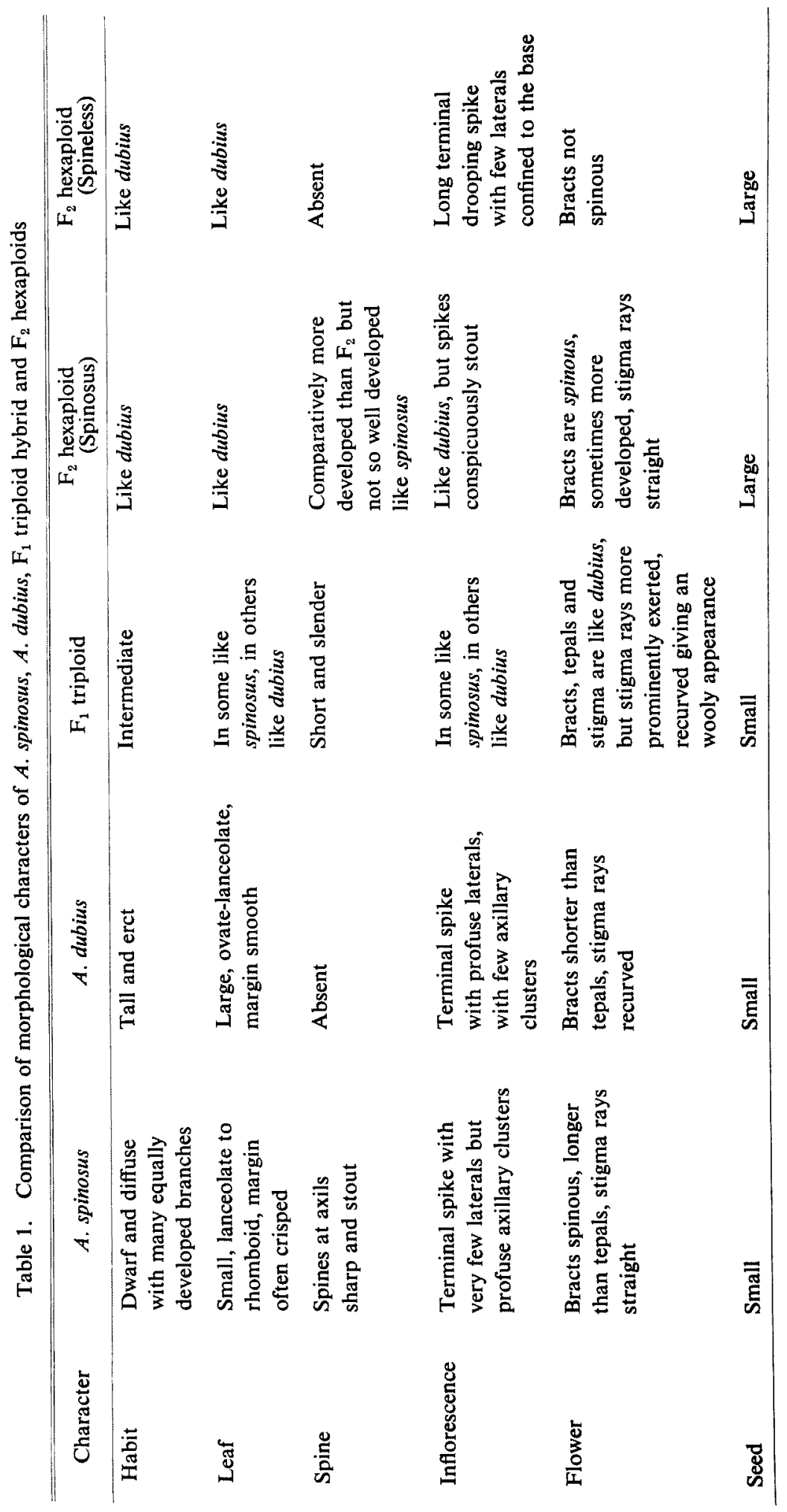


binomial expansion of $(p+q)^{24}$, where $p=$ the coefficient of realisation of bivalent association and $q=$ the coefficient of univalent formation, i.e. $(1-p)$. The Chisquare test for the goodness of fit was carried out.

The specimens have been deposited in the herbarium of the P. G. Department of Botany, Utkal University, Bhubaneswar.

\section{Results}

The triploid hybrids of $A$. spinosus $\times A$. dubius were intermediate in many characters between the two species whereas the hexaploid plants were more vigorous than either parent (Table 1). These triploids resemble A. spinosus in the nature of branching and leaf whereas it compares more closely to A. dubius in the type of inflorescence and flower arrangement. In the habit and pigment distribution it is somewhat intermediate between the two species. The axillary spines and spinous bracts which are conspicuous characters in A. spinosus and absent in A. dubius always develop in the triploid hybrid but in a reduced form. In the hybrids the spines in the axils are feebly developed and the bracts are not spinous. But the hexaploids resemble $A$.dubius in many characters such as habit, pigment pattern, branching, leaf, inflorescence and flower arrangement. On the otherhand the spines in the axils are stout and more developed than in the triploid and the bracts are also spinous. Thus in general while the triploid exhibits comparatively more characters of $A$. spinosus the hexaploid (Fig. 1A) more closely resembles $A$. dubius. Interestingly some of the characters of both the parents which were fully or partly suppressed in the triploid were again manifest in the hexaploid.

Of the 16 plants raised in the $F_{2}$ generation one plant was quite distinct by its peculiar type of inflorescence (Fig. 1B) and complete lack of spines in contrast to the very well developed spines in the $F_{1}$ and most other $F_{2}$ hexaploids. The stem was completely red with well developed betacyanin in contrast to the green stems of the normal hexaploids.

The cytological analysis of the triploid hybrids revealed 49 chromosomes in each pollen mother cells with various types of chromosomal associations (Table 2) ranging from $22^{1 \mathrm{II}}+5^{\mathrm{I}}$ to $4^{\mathrm{IV}}+9^{\mathrm{II}}+15^{\mathrm{I}}$ (Fig. 1D) with a very high frequency of $17^{\mathrm{II}}+$ $15^{\mathrm{I}}$ (Fig. 1C). Very often at metaphase while the bivalents are in the equatorial plane, the univalents are scattered and move earlier to the two poles. The variable chromosomal associations and large number of univalents result in an almost random separation of chromosomes at anaphase, though some cells were found with 24-25 separation. This is possibly responsible for the high degree of pollen and seed sterility.

All the 15 hexaploid plants of $A$. spinosus $\times A$. dubius raised by colchicine treatment of triploid hybrids were found to be characterised by $n=59$ (Fig. 2A). Variable numbers of multivalents were found during meiosis (Table 3). Disjunction, however, was fairly regular which may account for the high $(82.46 \%)$ seed fertility. Sex polymorphism was not seen in these plants.

The single spineless amphiploid plant was found to be cytologically different from the other hexaploids with the haploid chromosome number of $n=43$ (Fig. 2B). 
In this plant chromosomal association was like in the other hexaploids with the formation of varying numbers of quadrivalents, bivalents and nuivalents (Table 3).

The pollen and seed fertility were quite high like the hexaploids.

Seeds collected from both types of these amphiploids were sown for the $F_{3}$ generation which resulted in many different morphological types. Sex polymorphism was quite conspicuous in some of these plants which were completely female
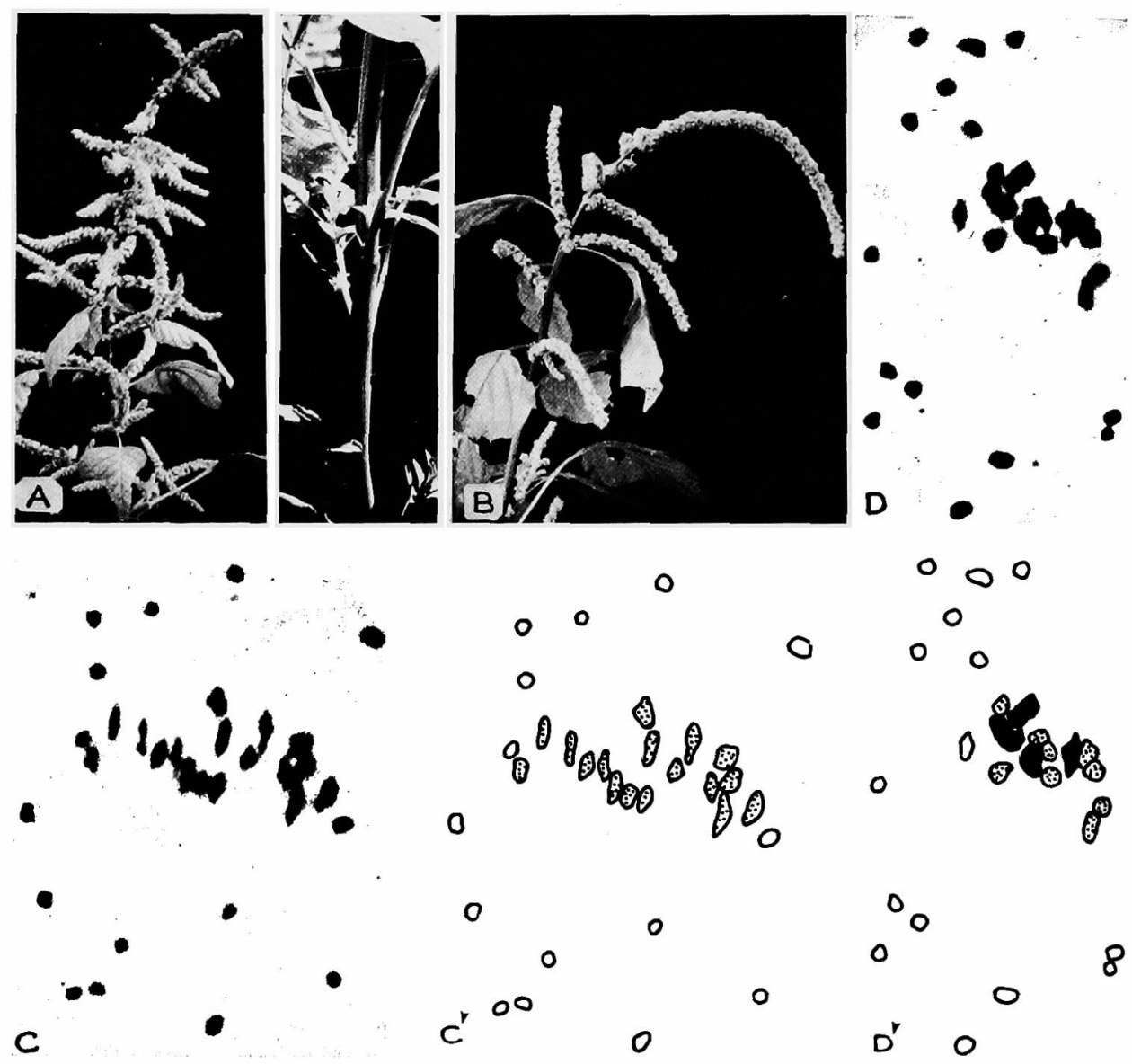

Fig. 1. A, shows the inflorescence and spines in the $\mathrm{F}_{2}$ hexaploid of A. dubius $\times$ A, spinosus. B, the inflorescence in the $\mathrm{F}_{2}$ spineless hexaploid of $A$.dubius $\times A$. spinosus. $\mathrm{C}$, a cell at metaphase $\mathrm{I}$ showing $17^{\mathrm{II}}+15^{\mathrm{I}}$ in the $\mathrm{F}_{1}$ hybrid of $A$. dubius $\times A$. spinosus. $\mathrm{D}$, a cell at metaphase $\mathrm{I}$ showing $4^{\mathrm{IV}}+9^{\mathrm{II}}+15^{\mathrm{I}}$ in the $\mathrm{F}_{1}$ hybrid of $A$, dubius $\times A$. spinous. $\quad \mathrm{C}^{\prime}-\mathrm{D}^{\prime}$, explainatory diagram to Fig. 1 .

plants without any male flowers. However plants with only male flowers have not been noticed. Seeds collected from spinous hexaploids gave rise to both spinous and spineless types of plants. A number of such plants were cytologically analysed. Most of the spinous plants resembled the hexaploid plants of the $F_{2}$ generation, many of which were characterised by $n=49$. Some spinous plants which were morphologically slightly different from the typical hexaploid were characterised 
by chromosome numbers varying from $n=45$ to $n=49$.

One such spinous plant in other respects resembling the $6 \mathrm{x}$ plant showed a certain variation in the nature of the inflorescence. In this plant the flowers were smaller and narrower and occurred on lower number per glomerule, with more aristate bracts and tepals. Cytological analysis of this plant revealed $n=45$.

Another interesting plant distinguished by its conspicuous light green leaves

Table 2. Frequency (number of cells) of different types of chromosomal associations in $\mathrm{F}_{1}$ hybrid of $A$. spinosus $\times A$. dubius in total number of 76 cells analysed from number of plants

\begin{tabular}{lcccc}
\hline \hline $\begin{array}{c}\text { Chromosome } \\
\text { configuration }\end{array}$ & Frequency & $\begin{array}{c}\text { Association in terms of bivalents and } \\
\text { univalents (one quadrivalent = two } \\
\text { bivalents) }\end{array}$ & $\begin{array}{c}\text { Frequency } \\
\text { of bivalent } \\
\text { realisation }\end{array}$ \\
\hline $22^{\mathrm{II}}+5^{\mathrm{I}}$ & 1 & $22^{\mathrm{II}}+5^{\mathrm{I}}$ & 2 & \\
$21^{\mathrm{II}}+7^{\mathrm{I}}$ & 3 & $21^{\mathrm{II}}+7^{\mathrm{I}}$ & 4 & $0.75^{*}$ \\
$20^{\mathrm{II}}+9^{\mathrm{I}}$ & 4 & $20^{\mathrm{II}}+9^{\mathrm{I}}$ & 6 & \\
$19^{\mathrm{II}}+11^{\mathrm{I}}$ & 4 & $19^{\mathrm{II}}+11^{\mathrm{I}}$ & 22 & \\
$18^{\mathrm{II}}+13^{\mathrm{I}}$ & 13 & $18^{\mathrm{II}}+13^{\mathrm{I}}$ & 32 & \\
$17^{\mathrm{II}}+15^{\mathrm{I}}$ & 23 & $17^{\mathrm{II}}+15^{\mathrm{I}}$ & 3 & \\
$16^{\mathrm{II}}+17^{\mathrm{I}}$ & 3 & $16^{\mathrm{II}}+17^{\mathrm{I}}$ & & \\
$1^{\mathrm{IV}}+19^{\mathrm{II}}+7^{\mathrm{I}}$ & 1 & & & \\
$1^{\mathrm{IV}}+18^{\mathrm{II}}+9^{\mathrm{I}}$ & 2 & & \\
$1^{\mathrm{IV}}+17^{\mathrm{II}}+11^{\mathrm{II}}$ & 3 & & \\
$1^{\mathrm{IV}}+16^{\mathrm{II}}+13^{\mathrm{I}}$ & 6 & & \\
$1^{\mathrm{IV}}+15^{\mathrm{II}}+15^{\mathrm{I}}$ & 5 & & \\
$1^{\mathrm{IV}}+18^{\mathrm{II}}+5^{\mathrm{I}}$ & 1 & & \\
$2^{\mathrm{IV}}+14^{\mathrm{II}}+13^{\mathrm{I}}$ & 1 & & \\
$2^{\mathrm{II}}+13^{\mathrm{II}}+15^{\mathrm{I}}$ & 2 & & \\
$3^{\mathrm{IV}}+12^{\mathrm{II}}+13^{\mathrm{I}}$ & 0 & & \\
$3^{\mathrm{IV}}+11^{\mathrm{II}}+15^{\mathrm{I}}$ & 1 & & \\
$4^{\mathrm{IV}}+10^{\mathrm{II}}+13^{\mathrm{I}}$ & 1 & & \\
$4^{\mathrm{IV}}+9^{\mathrm{II}}+15^{\mathrm{I}}$ & 1 & & \\
${ }^{*} 0.7^{\text {in }}$ case of Pal's data (1972, p. 111-Table 1) when calculated in the above manner.
\end{tabular}

Table 3. Chromosomal association in spinous and spineless amphiploids in $F_{2}$ generation

\begin{tabular}{|c|c|c|c|c|c|c|}
\hline \multirow{2}{*}{ Configuration } & \multicolumn{3}{|c|}{$\begin{array}{l}\text { Spinous amphiploid } \\
\text { (32 cells studied) }\end{array}$} & \multicolumn{3}{|c|}{$\begin{array}{l}\text { Spineless amphiploid } \\
\text { ( } 25 \text { cells studied })\end{array}$} \\
\hline & mean & range & mode & mean & range & mode \\
\hline Quadrivalents & $9.7 \pm 1.32$ & 4.18 & 10 & $6.2 \pm 0.85$ & 2.10 & 5 \\
\hline Bivalents & $26.9 \pm 1.77$ & 11.37 & 26 & $28.3 \pm 1.52$ & 17.36 & 29 \\
\hline Univalents & $5.4 \pm 1.25$ & 0.10 & 6 & $5.5 \pm 1.95$ & 2.95 & 4 \\
\hline
\end{tabular}

and lax type of inflorescence had peculiar type of spine arrangement. When young, it had spines near the base of the leaf on two sides of the axillary bud. With development of the axillary branch, however, one spine used to remain near the axil of the leaf, while the other spine shifted its position to the middle of the branch, to the side of a few axillary glomerule. Thus in the mature parts of the plant the spine appeared singly on one side at the axil of the leaf. This plant was character- 
ised by $n=42$ (Fig. $2 \mathrm{C}$ ) with a variable number of quadrivalents and univalents in different cells.

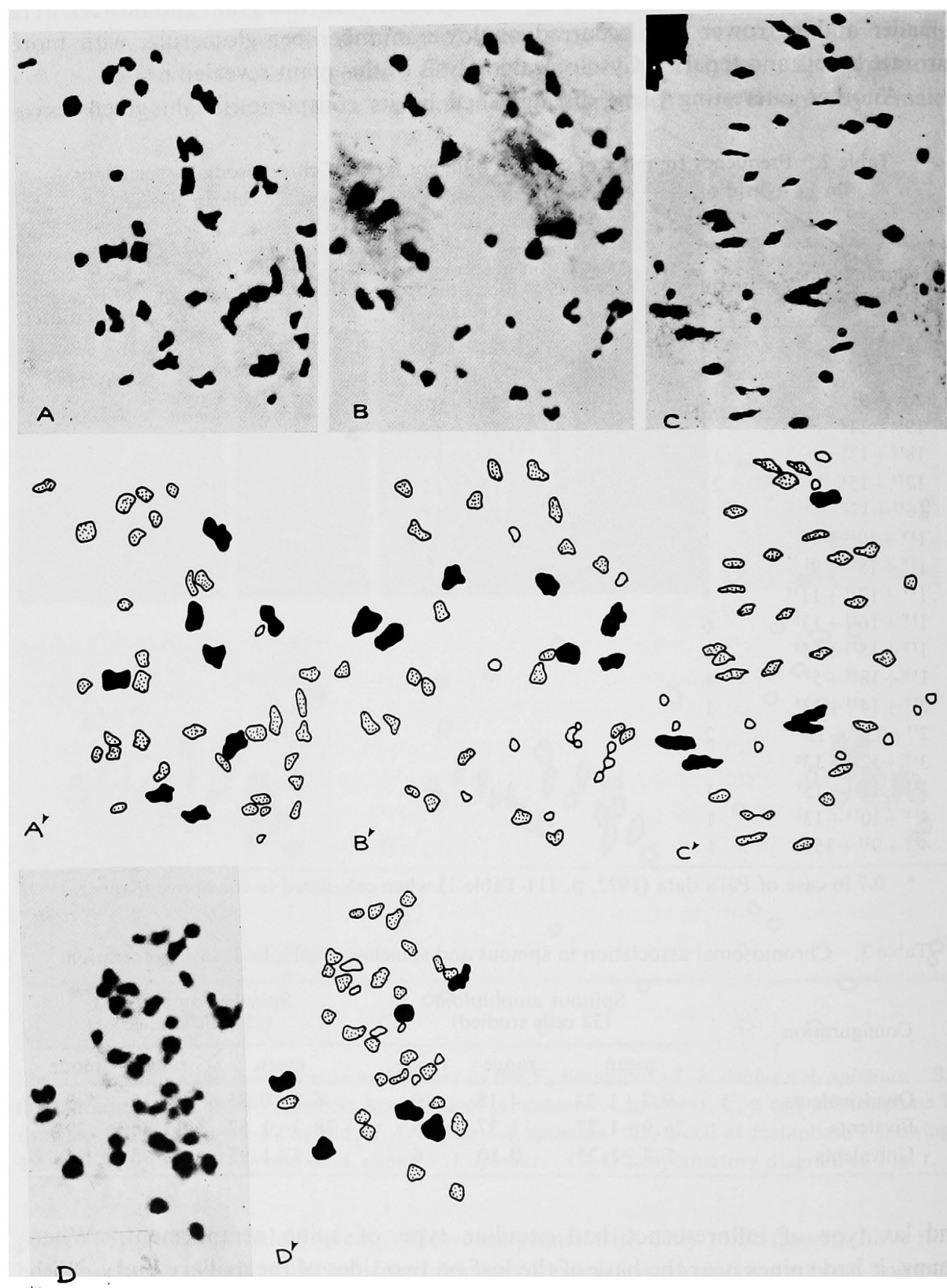

Fig. 2. A, showing $8^{\mathrm{IV}}+32^{\mathrm{II}}+2^{\mathrm{I}}$ in $\mathrm{F}_{2}$ spinous hexaploid. $\mathrm{B}$, a cell at metaphase $\mathrm{I}$ showing $7^{\mathrm{IV}}+2^{1 \mathrm{II}}+23^{\mathrm{II}}+6^{\mathrm{I}}$ in $\mathrm{F}_{2}$ spineless hexaploid. $\mathrm{C}$, a cell showing $5^{\mathrm{IV}}+27^{\mathrm{II}}+10^{\mathrm{I}}$ in $\mathrm{F}_{3}$ spinous hexaploid. D, a cell showing $6^{I^{\mathrm{V}}}+28^{\mathrm{II}}+4^{\mathrm{I}}$ in $\mathrm{F}_{3}$ spineless hexaploid. $\mathrm{A}^{\prime}-\mathrm{D}^{\prime}$, explainatory diagram to Fig. 2. 
The spinous plants arising from the seeds collected from spineless plants of the $F_{2}$ generation possibly through outcrossing with spinous hexaploids, revealed of chromosomes varying from $n=42$ to $n=45$.

The spineless plants arising both from selfing and open pollination were also characterised by less than the normal complements, ranging from $n=40-43$ (Fig. 2D).

Many other morphologically peculiar plants could not be studied due to the complete absence of male flowers in them. One such female plant was fully red and its stems and petioles completely spineless, vigorously branching and with spikes arising profusely throughout the stem.

\section{Discussion}

There are two contradictory views regarding the genome relationships of the two species, $A$. spinosus and $A$. dubius. On the basis of the chromosomal association in the triploid hybrid Grant (1959) was of the opinion that $A$. spinosus was possibly one of the parents of $A$. dubius in the past evolution of this species. Pal (1972) undertaking meiotic analysis in the triploid hybrid, hexaploids raised by colchicine treatment of the triploid and a polyhaploid accidentally obtained in the garden contradicted Grant's view on several grounds and expressed that it is reasonably clear that $A$. spinosus can not be one of the parents of tetraploid $A$. dubius. This question is re-examined during the present investigation where a number of triploid hybrids between these two species and the hexaploids raised through colchicine treatment and some aberrant plants arising in the hexaploid progeny were cytologically investigated.

The chromosome configurations during metaphase of meiosis $I$ in $F_{1}$ interspecific hybrids are usually taken as the criterion in judging the genome relationships between two species (Roy 1959) though it has been stated that "deductions from pairing must have an enormous margin of error" (Darlington 1937). Commenting on the chromosome pairing as measure of evolutionary ralationships, Stebbins (1971) also suggested that the complex series of interacting factors that determined pairing can vary in so many different ways that no quantitative index can be devised which would establish an absolute relationship between the degree of pairing of the chromosomes in an $F_{1}$ hybrid and the phylogenetic relationship between its parents. However, observing $17^{11}+15^{\mathrm{I}}$ in about $98 \%$ of the cells at metaphase in the triploid Grant (1959) held the view that the bivalents were due to allosyndetic pairing between the haploid complement of 17 chromosomes of $A$. spinosus and 17 out of the 32 chromosomes of $A$. dubius the remaining 15 chromosomes of $A$. dubius appearing as univalents. Pal (1972) observed $17^{11}+15^{\mathrm{I}}$ in $16 \%$ and $1^{1 \mathrm{r}}+15^{\mathrm{II}}+13^{\mathrm{I}}$ in $48 \%$ of cells and thought that "the occurrence of high number of bivalents" might be due to autosyndetic pairing. This has also been substantiated by the finding of some bivalents in the polyhaploid plant of $A$. dubius. As Pal (l.c.) observed very few quadrivalents $(0-4)$ in the amphiploid which were far from the corresponding number of 17 , he concluded that the pairing in the $F_{1}$ triploid was between homoeologous chromosomes within the $A$. dubius genome. During 
the present study, however, a large number of cells had $17^{11}+15^{\mathrm{I}}$ in the $F_{1}$ triploid and as many as 18 quadrivalents (range $4-18$ ) have been noticed in the amphiploid. Occurrence of univalents and a lower number of quadrivalents than expected in such amphiploids and even in autopolyploids is not an unusual feature and have been assumed to be due to many reasons such as preferential pairing (Riley and Law 1965), mechanical intereference (Upcott 1939) or evolutionary adaptation (Manton 1950). As Stebbins (1971) suggested, this tendency is more likely in plants with smaller chromosomes and lower chiasma frequency. In a recent study (Behera and Patnaik 1975), induced autopolyploid plants of $A$. dubius revealed a range of 6-19 and a mean of $12-45$ quadrivalents per cell in $\mathrm{C}_{0}$ generation in contrast to the

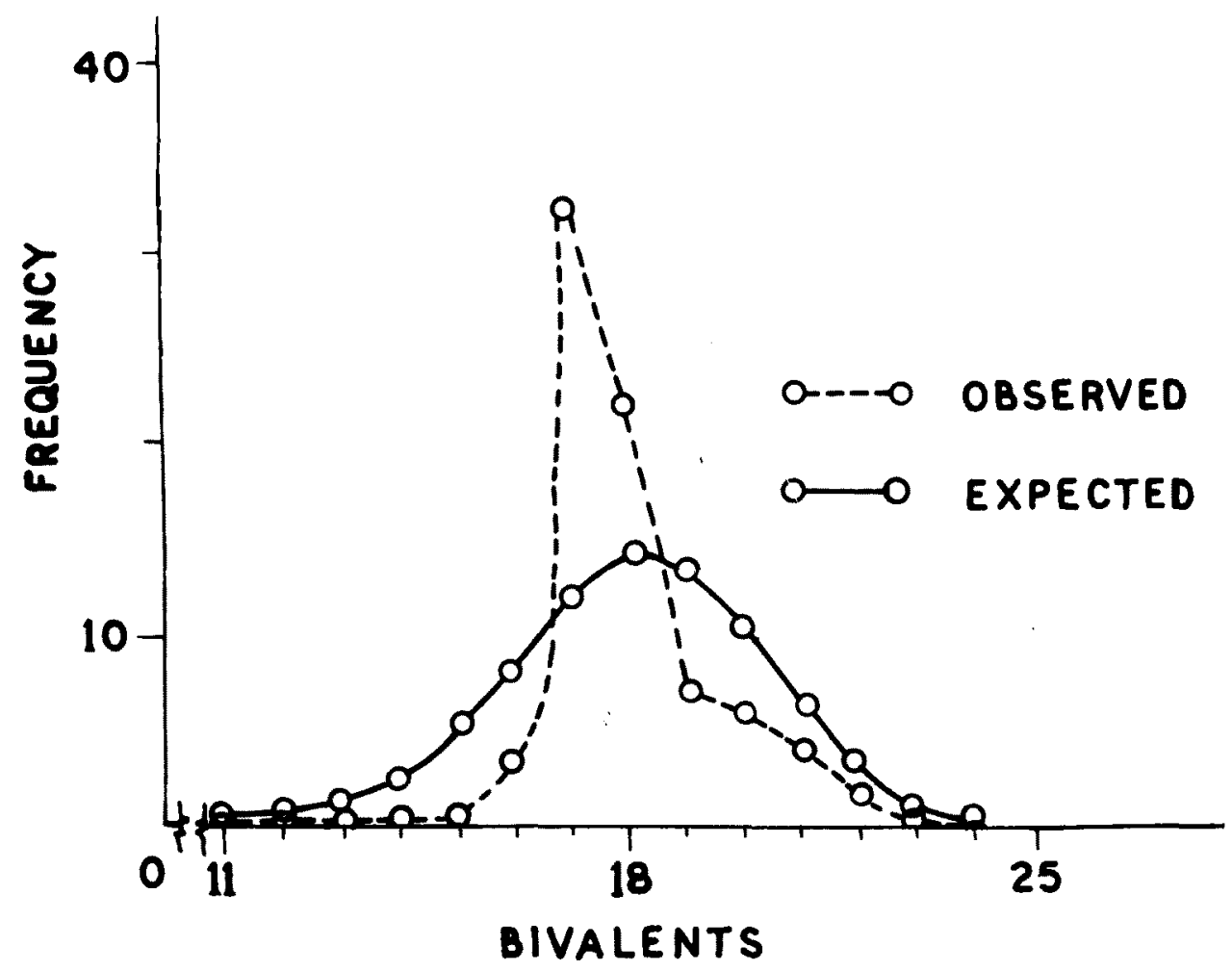

Fig. 3. graphs showing expected and observed binomial distribution of bivalents in $A$. dubius $\times$ A. spinosus hybrids.

expected maximum number of 32 quadrivalents. Thus in view of this finding allosyndetic pairing in the hybrid can never be ruled out and on the contrary might be more plausible than autosyndetic pairing. However, if one assumes only allosyndetic pairing to occur, there would be a maximum of 17 bivalents resulting from 17 chromosomes of spinous genome and 17 out of 32 chromosomes of the dubius genome. On the otherhand if only autosyndetic pairing within the dubius genome is visualised there would be a maximum of 15 or 16 bivalents depending on the allo- or autopolyploid origin of the dubius genome. But the record of as many as $22^{\text {II }}$ or $1^{11}+19^{11}$ is highly suggestive of the presence of three sets of genomes 
in the hybrid with both auto- and allo-syndeitic pairing in which case $24^{1 \mathrm{II}}$ are also theoretically possible. On this assumption when $(p+q)^{24}$ is binomially expanded with a coefficient of bivalent realisation or $p=0.75$ ( 0.7 in case of Pal's data) and a coefficient of univalent formation or $q=0.25$, the observed frequencies were found to be strongly deviating from the expected frequencies of distribution (Fig. 3). The pattern of deviation had three important attributes: i) the resulting distribution is unimodal, ii) the expected frequencies at the ends are less than those under the binomial distribution and iii) the expected frequencies in the middle are higher than those under the binomial distribution which strictly corresponded to those envisaged under Mode. 1 by Sreenath and Sinha (1968). This is highly suggestive of preferential pairing of groups of chromosomes and in the observed frequency distribution 17 being the modal value it is quite likely that 17 spinosus chromosomes have a genetically comparable set represented within the dubius genomes.

One difficulty in accepting $A$. spinosus as one of the parents of $A$. dubus is that with the haploid number of $\mathrm{n}=17$ in $A$. spinosus, the other parent should have been a species characterised by $n=15$. In the absence of any species within the genus characterised by the haploid chromosome number of $n=15$, Grant (1959) conjectured that another species either with $n=16$ or $n=17$ might have acted as the other parent and after the amphiploid had been derived with $n=33$ or $n=34$, the present day $A$. dubius with $\mathrm{n}=32$ would have been stabilized after a loss of 1 or 2 pairs of chromosomes. This possibility is not entirely ruled out because there is enough evidence to show that aneuploidy has played a great role in the speciation in a large number of plants.

Another objection was raised by $\mathrm{Pal}$ (1.c.) against Grant's postulation viz. the lack of spines in $A$. dubius, an important morphological maker characterising only A. spinosus in the whole genus Amaranthus. This character is always expressed in the triploid hybrid and develops even more prominently in the hexaploid. The absence of spine in $A$. dubius as well as in the polyhaploid (which was considered by $\mathrm{Pal}$ to be theoretically the nearest condition to the $\mathrm{F}_{1}$ which might have given rise to $A$. dubius in the past) has been argued by $\mathrm{Pal}(\mathrm{l} . \mathrm{c})$ as an evidence against $A$. spinosus being considered as one of the parents of $A$. dubius.

Interestingly enough an aberrant plant with different cytotype within the synthetic amphiploid population was obtained which is a pointer in this direction. This plant was found to have undergone a loss of six pairs of chromosones from the normal complement of $n=49$ in the rest of the hexaploids. This loss of chromosomes is probably due to deficient gametes resulting from irregular disjunction. This loss possibly could be endured due to the high polyploid level as a result of which the pollen and seed fertility were quite high in this secondary aneuploid plant and comparable to those of the other hexaploids. This plant was interesting because of the complete absence of spine both from the axil of the leaf as well as from the bract in contrast to the well developed spines in the other hexaploids. The loss of spines in this plant may be visualised to be due to the loss of chromosomes and quite likely the chromosome determining the spine. Thus in view of this finding the two major objections which were raised by Pal (1.c.) that we have to assume the loss of chromosomes and the loss of spine for considering A. spinosus 
as one of the parents of $A$. dubius need not be taken very serious, since the loss of chromosomes and loss of spine in the same plant may not be two events. Again since the expression of the spiny character increases with gene dose, there is a possibility that in the hybrid background of $A$. spinosus with the undefined other parent the dose of two "spiny" alleles is not enough to give an expression. With an additional dose as in the triploid hybrid, there are enough alleles for expression and in the hexaploid this is increased. Thus while it may be "too much to assume that the spines in the present day A. spinosus were acquired after its involvement in the origin of A.dubius," the loss of spine through chromosomal loss or due to hybridity after its synthesis is not difficult to visualise. It has also been pointed out by $\mathrm{Pal}$ (l.c.) that the distinctive flower arrangement in A. spinosus is absent in A. dubius. The very distinctive type of inflorescence (Table 1 ) in the spineless amphiploid compared to the other hexaploids is again suggestive in this direction. In this connection it may be mentioned that recently a trisomic plant $\left(n=32^{1 \mathrm{II}}+1^{\mathrm{I}}\right)$ experimentally obtained through induced translocation showed marked variation from the normal $A$. dubius in the nature of the panicle.

In the $\mathrm{F}_{3}$ generation varied types of plants were found differing from the normal hexaploids in the nature of inflorescence, spine and betacyanin development and sex polymorphism. Cytological analysis of a number of such plants revealed less than the normal complement of $n=49$ which might have arisen either through back cross, with $A$. dubius or through the fusion of dificient gametes. Plants showing sex polymorphism could not be studied because all of these were fully female plants. Some of them were also completely spineless. While determination of chromosome numbers in such plants may throw some light on this disturbance of sex expression, it is presumed that loss of some chromosomes may disturb the intricate balance between the sex factors which are probably positioned in different chromosomes. As Westergaard (1958) held, the bisexual state is probably the original one and dioecious species have originated from hermaphrodite or monoecious species. He postulated that dioecious species might be derived from bisexual ones only by having developed a trigger mechanism, which suppresses the potentialities of the opposite sex in males and females. Thus in these hybrid plants quite likely loss of chromosomes which are very frequent might be responsible for the development of such a trigger. Grant (1959) unable to locate any heteromorphic sex chromosomes in dioecious species of Amaranthus was also of the opinion that the dioecious condition has most likely arisen as a result of hybridisation which has brought together the required genic conditions for its expression.

\section{Summary}

Hybrids between Amaranthus spinosus L. $(\mathrm{n}=17)$, a diploid and $A$. dubius Mart. ex Thell. $(\mathrm{n}=32)$, a tetraploid compared to $A$. spinosus frequently arise in nature where both the species grow together. Cytological analysis of such triploid hybrids, the hexaploids raised through colchicine treatment and certain deviant hexaploids, mainly found among the progeny of the second and third generation hexaploids revealed interesting genome relationships between $A$. dubius and $A$. 
spinosus. In the pollen mother cells of the triploid hybrid $(2 n=49)$ various types of chromosomal associations could be seen ranging from $22^{\mathrm{II}}+5^{\mathrm{I}}$ to $4^{\mathrm{IV}}+9^{\mathrm{II}}+15^{\mathrm{I}}$ with a high frequency of $17^{1 \mathrm{I}}+15^{\mathrm{I}}$. In view of this the possibilities of only autosyndesis or only allosyndesis were eliminated and this was strongly suggestive of the presence of three sets of genomes in the triploid hybrid with both auto- and allosyndesis. The observed frequency of bivalent distribution was strongly deviating from the expected frequency of binomial distribution and the pattern of deviation with a modal value of 17 bivalents may suggest that a set of chromosomes genetically comparable to those of $A$. spinosus is present within $A$. dubius genome.

\section{Acknowledgements}

This work was supported by the University Grants Commission, New Delhi, India. The authors wish to thank Dr. B. Padhi, Professor and Head, Department of Botany, Utkal University for providing laboratory facilities and Dr. S. K. Sinha, Professor of Botany, O.U.A.T. for his valuable suggestions.

\section{Literature cited}

Behera, B. and Patnaik, S. N. 1975. Induced polyploidy in Amaranthus hypochondriacus L. and A. dubius Mart. ex Thell. Cytologia 40: 157-168.

Clifford, H. T. 1959 . On hybridization between Amaranthus dubius and A. spinosus in the vicinity of Ibadan, Nigeria. J. West. Afr. Sci. Assoc. 4: 112-116.

Darlington, C. D. 1937. Recent Advances in Cytology. 2nd edn. London.

Grant, W. F. 1959. Cytogenetic studies in Amaranthus II. Natural interspecific hybridization between Amaranthus dubius and A. spinouss. Canad. J. Bot. 37: 1063-1070.

Manton, I. 1950. Problems of Cytology and Evolution in the Pteridophyta. University Press. Cambridge. England.

Pal, M. 1972. Evolution and improvement of cultivated Amaranthus III. Ameranthus spinosusdubius complex. Genetica 43: 106-118.

Riley, R. and Law, C. N. 1965. Genetic variation in chromosome pairing. Adv. Genet. 13: 57-114.

Roy, R. P. 1959. Genome analysis of Aegilops spharonensis. Genetica 29: 331-357.

Screenath, P. R. and Sinha, S. K. 1968. An analysis of chromosomal behaviour during meiosis in asynaptic maize I. Distribution of bivalents. Cytologia 33:69-72.

Stebbins, G. L. 1971. Chromosomal Evolution in Higher Plants. Bristol. England.

Thellung, A. 1914. Amaranthus. In: P. A. Scherson and P. Graebner. Synopsis der mitteleuropaischen Flora 5: 225-356. Lipzig.

Upcott, M. B. 1939. The nature of tetraploid in Primula kewensis. Jour. Genet. 39: 79-100.

Westergaard, M. 1958. The mechanism of sex determination in dioecious flowering plants. Advances in Genetics 9: 217-281. 